\title{
Geographical distribution and epidemiological characteristics of visceral leishmaniasis in Bulgaria, 1988 to 2012
}

R Harizanov (harizanov@ncipd.org) ${ }^{1}$, I Rainova ${ }^{1}$, N Tzvetkova' ${ }^{1}$ I Kaftandjiev ${ }^{1}$, I Bikov ${ }^{1}$, O Mikov $^{1}$

1. National Centre of Infectious and Parasitic Diseases (NCIPD), Department of Parasitology and Tropical Medicine, Sofia, Bulgaria

Visceral leishmaniasis is a sporadic illness in Bulgaria. However, cases in humans are registered nearly every year. This study describes the geographical distribution of the disease in Bulgaria from 1988 to 2012, over a period of 25 years. Cases were analysed according to age, sex, and place of residence. A total of 122 cases were registered in 25 years, 118 of which were autochthonous and four of which were imported from endemic countries in southern Europe. The average annual incidence for the study period was 0.06 per 100,000 population, or an average of five cases per year (maximum 15 in 1989; no cases notified in 1991, 1995, 1996 and 2008). Cases of visceral leishmaniasis were recorded in 13 out of 28 regions in Bulgaria, mainly in the southern part of the country. The highest number of cases were registered in the regions of Blagoevgrad $(n=36)$ and Stara Zagora $(n=34)$. Data presented in this study show that there is ongoing transmission of visceral leishmaniasis in Bulgaria with a high mortality rate (1:7), affecting mostly children.

\section{Introduction}

Visceral leishmaniasis (VL) is a protozoan, vectorborne disease characterised by chronic course, remittent fever, hepatosplenomegaly, and anaemia to complete pancytopenia and secondary immunosuppression. Leishmania infantum is the causing agent of $\mathrm{VL}$ in the Mediterranean region. In areas endemic for $\mathrm{VL}$, the disease tends to have a chronic course and children are especially affected [1]. The average incubation period of the disease varies from a few weeks to six months. Until recently, children aged between one and four years were the group most affected by endemic VL caused by L. infantum in southern Europe, North Africa, west and central Asia [2]. According to some authors, the ratio between children and adults with leishmaniasis in the Mediterranean region is $7: 3$ and the average age of the affected children is under four years [3]. However, in recent years, about a half of leishmaniasis cases in Europe have occurred in adults, following the appearance of the human immunodeficiency virus (HIV) infection and the increased number of patients receiving immunosuppressing treatments due to transplantation, malignancies or other underlying conditions [4].

The first cases of VL in Bulgaria were reported by Mollov in 1921, who then described two clinical cases imported from Greece, and in 1937, the same author described the first autochthonous VL case in the country [5]. In the following 16 years, until 1953, a total of 57 autochthonous cases of VL were reported in Bulgaria, 50 of which were children. At that time, the disease occurred sporadically, mostly in the southern part of the country $[6,7]$. Between 1953 and 1988, only sporadic cases of $\mathrm{VL}$ were registered in the country. This was attributed to the mass use of dichlorodiphenyltrichloroethane, an organochlorine insecticide used during the eradication of malaria in Bulgaria, which led to the decrease in number and density of mosquitoes and phlebotomine sandflies that serve as vectors for leishmaniasis [8].

Studies on VL cases in Bulgaria were mainly focused on clinical aspects, diagnosis and treatment [9-13]. Over the last 15 to 20 years, the incidence of VL in Bulgaria increased significantly and the disease is now present in most parts of the country. Since 1988, autochthonous VL cases are registered almost annually.

Dogs are the principal reservoir hosts of $L$. infantum under domestic and peridomestic conditions [2]. In recent years, several studies on canine VL in Bulgaria were conducted. In 2004, a seroepidemiological screening for leishmaniasis among dogs was performed in 11 regions in Bulgaria: five regions in southern Bulgaria (Plovdiv, Stara Zagora, Yambol, Burgas, Blagoevgrad) and six regions in northern Bulgaria (Varna, Silistra, Ruse, Veliko Tarnovo, Pleven, Montana) (Figure 3) [14]. Sera from 220 dogs were tested by immunofluorescent assay, but none was seropositive. In 2006, clinical manifestations of leishmaniasis were observed and described in two domestic dogs in Petrich in southwestern Bulgaria [15]. In 2007, a seroepidemiological 
Notified cases of visceral leishmaniasis, Bulgaria, 1988-2012 ( $\mathrm{n}=122)$

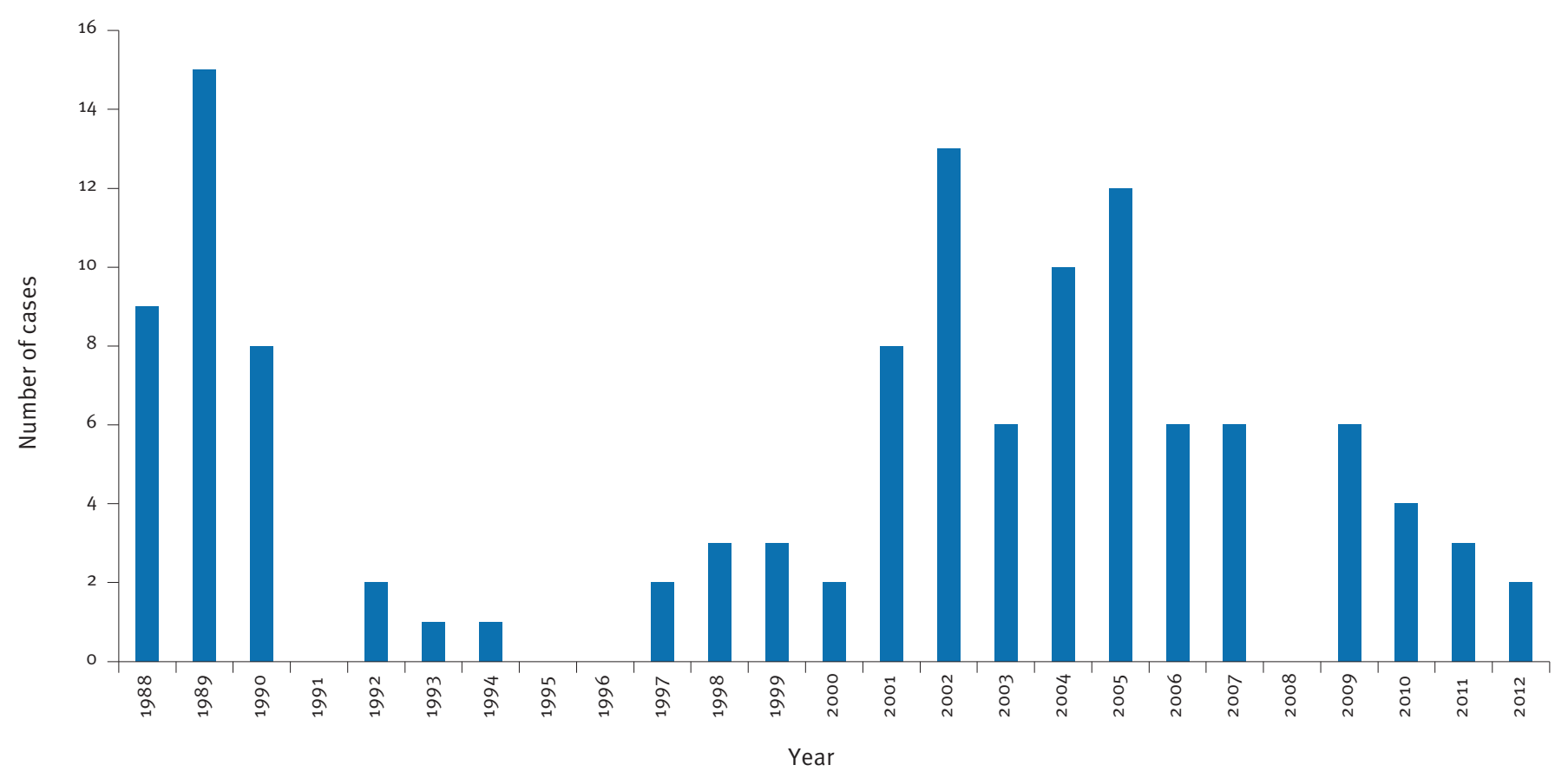

survey on the seroprevalence of $L$. infantum among dogs was carried out in two municipalities - Svilengrad and Petrich. Ten new cases of canine VL with clinical manifestations were diagnosed between November 2006 and November 2007 in these two municipalities [16].

There are no recent data on species composition of the phlebotomine sandfly fauna in Bulgaria. Few publications on the subject exist from the beginning of the 2oth century and a single more recent study from 2011. Five species of the genus Phlebotomus were identified in the country so far: Phlebotomus papatasi, Ph. sergenti, Ph. perniciosus [17], Ph. balcanicus [18], and Ph. tobbi [19]. Ph. perniciosus is considered as a main vector, and $P h$. balcanicus and $P h$. tobbi are considered as potential vectors of VL [20].

The aim of the present study is to describe and summarise data from all registered cases of VL in Bulgaria from 1988 to 2012, by demographic information and geographic distribution and to compare the results with those published for other endemic European countries.

\section{Methods}

According to the Bulgarian legislation, VL is a mandatorily notifiable disease since 1978 [21]. Notification and registration of all cases of $V L$ are regulated in two ordinances $[22,23]$. All cases of $V L$ are reported to the regional health inspectorate $(\mathrm{RHI})$ by the diagnosing physician. Each case must be confirmed by additional tests at the Department of Parasitology and Tropical Medicine (DPTM) at the National Centre of Infectious and Parasitic Diseases (NCIPD), Sofia. According to the legislation [23] cases of infectious diseases are classified into the following categories: possible, probable, and confirmed. Only confirmed cases of VL are subject to mandatory notification. RHI submits a summary of all recorded cases to the National Health Information Centre on a daily basis. The Centre processes the data collected from RHIs and sends a monthly summary of the situation to the Ministry of Health, the NCIPD, and the RHIs. Every year, the DPTM at NCIPD analyses the parasitic morbidity in the country. Based on this information, the Ministry of Health takes measures aimed at increasing the effectiveness of the surveillance system. Surveillance for VL comprises a set of activities including an epidemiological investigation of the cases on site and filling in a registration card. After treatment, the patients are subject to follow-up for one year.

For this study we used (i) data from registration cards of VL cases, (ii) data from the annual analyses of the parasitic morbidity in the country released by NCIPD each year and (iii) data from the clinical exams of patients checked at the DPTM at NCIPD.

The registration cards contain personal information, medical history, clinical and laboratory data, epidemiological and treatment information and data from parasitological laboratory tests.

We conducted a retrospective analysis of the medical records of the confirmed VL cases (both autochthonous and imported) in Bulgaria. The incidence per 100,000 population was calculated on the basis of 
the information available from the National Statistical Institute about the number of the Bulgarian population per years $[24,25]$.

With the existing surveillance system in Bulgaria, underreporting of diagnosed VL cases is unlikely. Based on this, we consider the limitations or bias in this study as minimal. An approval from the ethical commission was not necessary for this study.

\section{Results}

During the study period, 122 cases of VL were registered (Figure 1). Of these, 118 were autochthonous with patients from 51 settlements (urban and rural) in 13 of the 28 regions in Bulgaria. Four imported cases were recorded in Bulgarian citizens who had visited European countries in the Mediterranean region [9-11,26].

Cases of VL were registered in all years between 1988 and 2012, except for 1991, 1995, 1996 and 2008. The peaks of incidence were in 1989 ( $n=15$ cases), 2002 $(n=13), 2005(n=12), 2001(n=10)$ and $2004(n=10)$.

Throughout the years we could observe that the incidence of VL was fluctuating. In different periods as in 1988-1990, 2001-2007 and 2009 the incidence was higher compared to the established average annual incidence of 0.06 per 100,000 population for the whole period (Figure 2).
Age and sex distribution

Sixty-eight (56\%) of the 122 patients were children and teenagers up to 18 years of age, and 54 (44\%) adults. When analysing the age among children we found that the most affected group were children between one and two years of age $(n=18)$, followed by children under one year $(n=15)$. The group of children between zero and five years of age prevails among all persons with VL $(n=48 ; 71 \%$ of cases among children and $39 \%$ of the total number of cases). The average age of the affected children in Bulgaria is 4.7 years. Ninety-one ( $75 \%)$ of the cases were male.

\section{HIV co-infection}

Among the 54 adults diagnosed with VL, only one person was co-infected with human immunodeficiency virus (HIV).

\section{Mortality}

Seventeen people (13.9\%) died from VL during the study period. The highest number of deaths $(n=9)$ was registered in 1989. Average annual mortality for the whole period 1988 to 2012 was 0.01 per 100,000 population.

\section{Seasonality}

Cases of VL were recorded in all months of the year. In more than a half of the cases (61 of the 118 autochthonous cases) the first clinical symptoms were noticed during the months from October to January.

\section{FIGURE 2}

Incidence of notified cases of visceral leishmaniasis per 100,000 population, Bulgaria, 1988-2012 $(n=122)$

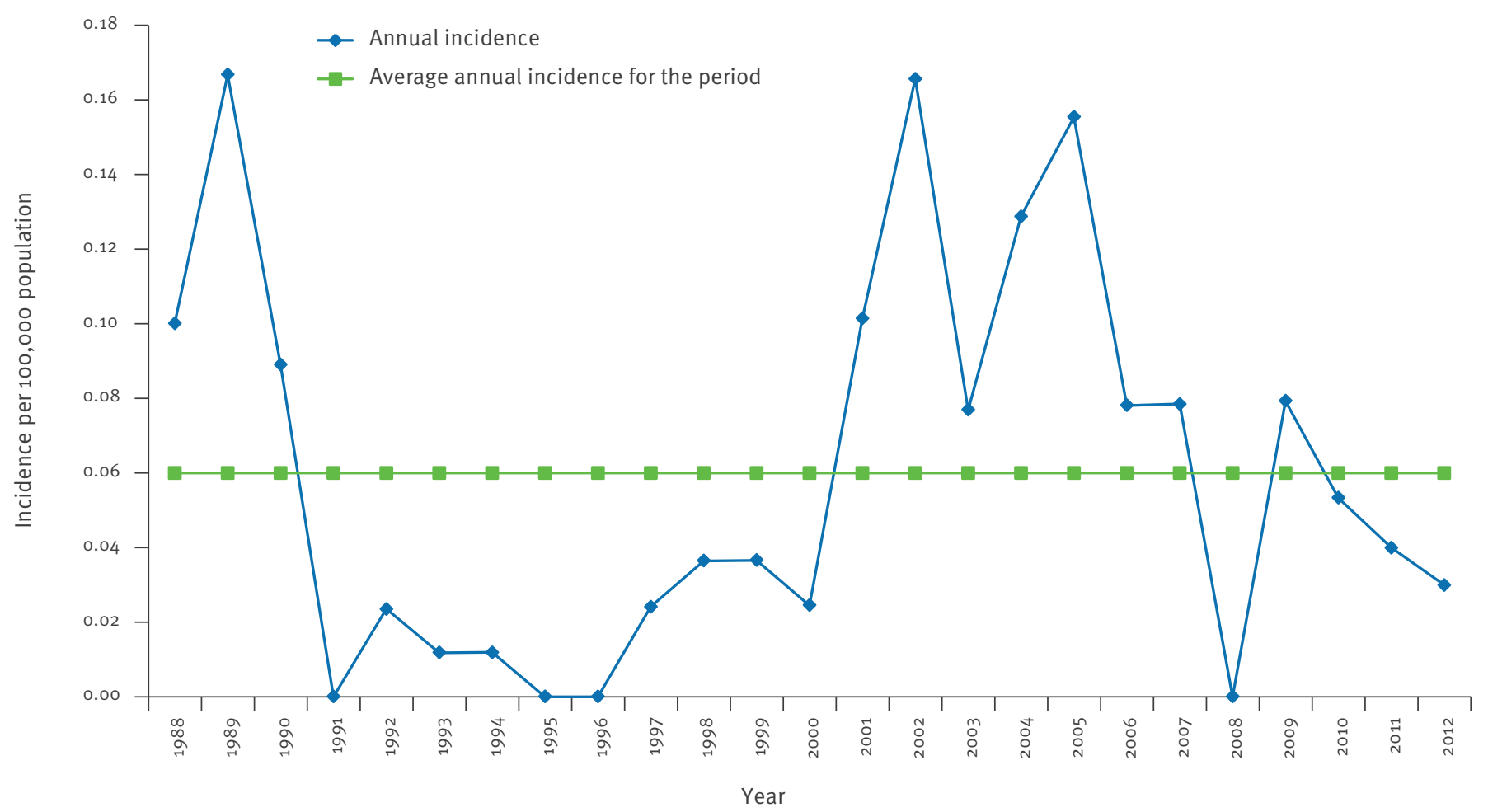


Visceral leishmaniasis cases by age, sex, residence, and place of infection, Bulgaria, 1988-2012 ( $\mathrm{n}=122)$

\begin{tabular}{|l|c|c|c|c|c|c|c|c|}
\hline \multirow{2}{*}{ Characteristic } & \multicolumn{2}{|c|}{ Age } & \multicolumn{2}{c|}{ Sex } & \multicolumn{2}{c|}{ Residence $^{\text {a }}$} & \multicolumn{2}{c|}{ Place of infection $^{\text {Chen }}$} \\
\cline { 2 - 10 } & Children & Adults & Men & Women & City & Village & Autochthonous & Imported \\
\hline Number of cases & 68 & 54 & 91 & 31 & 82 & 36 & 118 & 4 \\
\hline Percentage\% & 56 & 44 & 75 & 25 & 69 & 31 & 97 & 3 \\
\hline
\end{tabular}

${ }^{a}$ For autochthonous cases only ( $\left.\mathrm{n}=118\right)$.

\section{FIGURE 3}

Autochthonous human cases of leishmaniasis $(n=118)$ and results of seroepidemiological screening of dogs by region, Bulgaria, 1988-2012

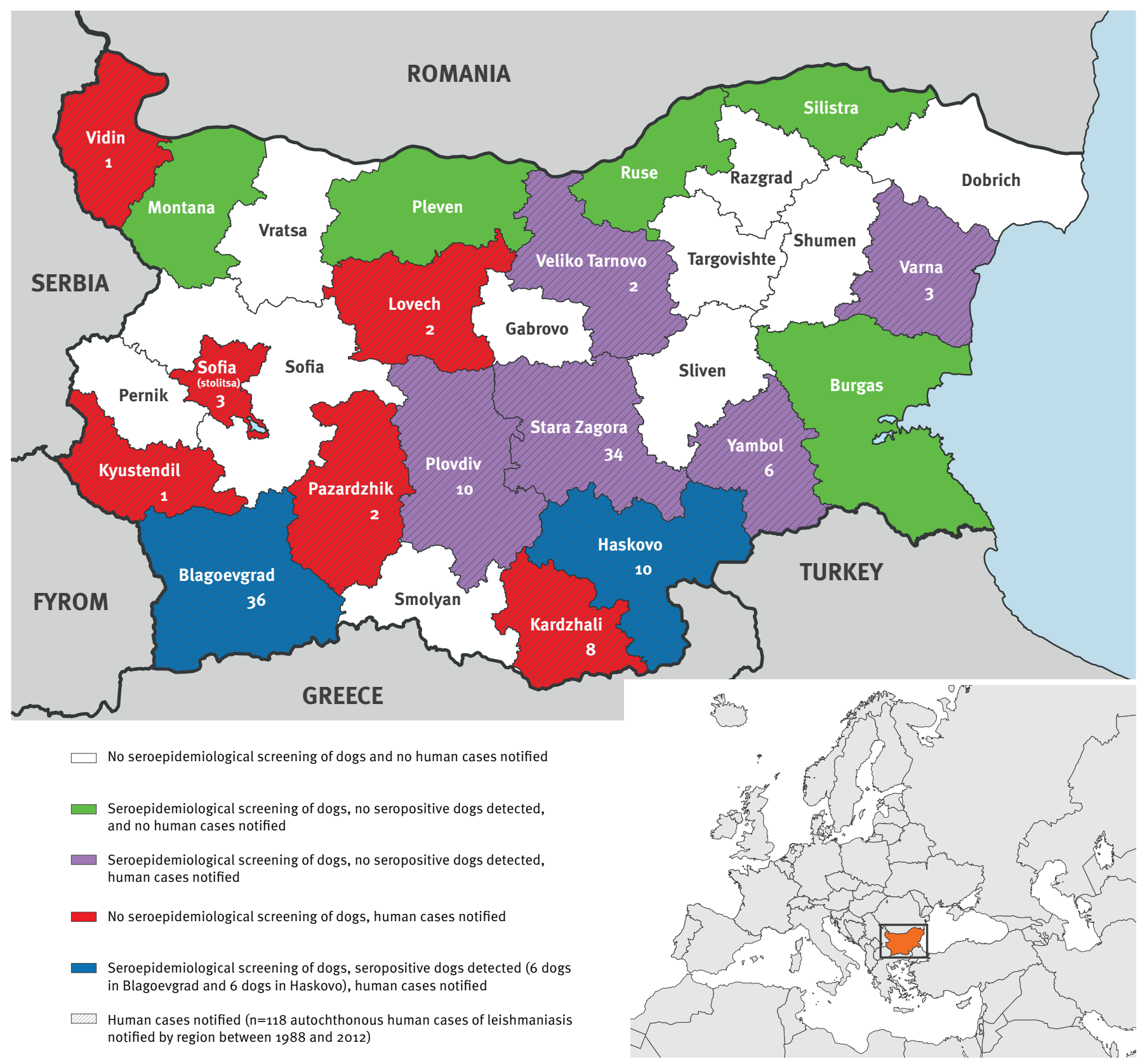


Autochthonous and imported cases

The majority of cases $(n=118 ; 97 \%)$ were autochthonous. In 2006 and 2007 four (3\%) imported VL cases were registered in Bulgarian citizens, two of whom had travelled to Italy and two to Spain.

\section{Residence and geographical}

distribution of cases

In terms of the type of residence in which the cases lived, $82(69 \%)$ of them lived in urban and $36(31 \%)$ in rural settlements (Table).

Cases of VL were recorded mainly in southern Bulgaria (Upper Thracian Plain and the Valley of Struma River), but cases of VL occurred also in northern Bulgaria indicating that the whole territory of the country is potentially endemic.

Figure 3 shows the notified autochthonous VL cases by region of residence. The highest number of autochthonous cases $(n=96 ; 81 \%)$ was recorded in urban and rural settlements located at altitudes below 300 meters and typically with hilly landscape.

\section{Discussion}

In this paper we studied the distribution of $V L$ in Bulgaria over a 25-year period from 1988 until 2012. The vast majority of patients were autochthonous cases and this is convincing evidence for the presence of local transmission of VL in rural and urban areas. Although Bulgaria is not situated in the Mediterranean, there are favourable environmental conditions for local transmission of the disease. Our results showed that most cases were probably infected during the warmer months of the year (June-October) when phlebotomine sandflies are active.

The average age of the affected children in Bulgaria ( 4.7 years) is similar to the Mediterranean countries. Most of the patients lived in urban areas and a possible explanation for this finding could be that some of the sylvatic foci are located close to the cities with recorded cases. Most people living in cities in Bulgaria are closely linked to the rural settlements because they have relatives living there and visit them often (farming, hunting, recreational activities). The fact that they visit the villages often for various activities means that they are more frequently in contact with these foci.

Only one case of HIV/VL co-infection was recorded. Although HIV-testing was not performed in all patients, we consider this number correct because in the follow-up observation for at least one year, no cases of relapse have occurred and all adult patients were definitely cured. Furthermore, this assumption may be supported to some extent by the low number of HIVpositive people in Bulgaria. According to the National Program for Prevention and Control of HIV/acquired immunodeficiency syndrome (AIDS) at the Bulgarian Ministry of Health, by the end of 2012, the total number of officially registered persons living with HIV/AIDS in the country was 1,647 [27]. This is different from other countries in southern Europe where in the past up to $70 \%$ of the cases of VL in adults were associated with HIV infection, and HIV/VL co-infection was distributed mostly among adults where $77.3 \%$ of the recorded cases with co-infection affected the age group between $31-50$ years old $[4,28]$. The incidence of new VL cases in HIV-positive patients dropped about 50 to $65 \%$ in the Mediterranean area after highly active antiretroviral therapy (HAART) was introduced [29].

Even though cases occurred in nearly all parts of the country, most VL cases during the study period (110 of the 118 autochthonous cases) occurred among residents of the southern part of the country and the highest number of cases was found in south-western Bulgaria (Blagoevgrad region) and central-southern Bulgaria (Stara Zagora). The presence of single cases of $V L$ in the northern part of the country is probably due to the very similar climatic, geographic and faunistic features of the separate geographical zones in Bulgaria which define the epizootology and epidemiology of the disease. Another potential explanation could be the fact that people living in the northern part of the country have acquired the infection while travelling in the rural regions of the south.

Still considered by some as a tropical disease, zoonotic $V L$ is endemic in a number of southern European countries. Cases of VL have been recorded in all countries neighbouring Bulgaria: Turkey, Greece, Romania, Serbia and the former Yugoslav Republic of Macedonia $[30,31]$. In southern Europe the incidence is relatively low: 0.02-0.49 per 100,000 population (estimated at around 700 new cases per year) [32]. Our data are in line with these estimates: the average incidence of VL from 1988 to 2012 is 0.06 per 100,000 population and new cases of the disease are recorded locally almost every year.

Although the incidence of VL in Bulgaria is relatively low, its severe course and the possibility of a lethal outcome is a reason to regard leishmaniasis as an illness with high impact on public health.

Conflict of interest

None declared.

References 
1. Fenech FF. Visceral leishmaniasis in the Mediterranean. J Trop Med Hyg. 1976;79(4):85-8. PMid:933225

2. World Health Organization (WHO). Control of the leishmaniasis: report of a meeting of the WHO Expert Committee on the Control of Leishmaniases, Geneva, 22-26 March 2010. Geneva: WHO. 2010. Available from: http://whqlibdoc.who.int/trs/ WHO_TRS_949_eng.pdf

3. Cruz I, Chicharro C, Nieto J, Bailo D, Canavate C, Figueras M-C, et al. Comparison of New Diagnostic Tools for Management of Paediatric Mediterranean Visceral Leishmaniasis. J Clin Microbiol. 2006;44(7):2343-7. http://dx.doi.org/10.1128/ JCM.02297-05. PMid:16825347. PMCid:PMC1489479.

4. Desjeux P, Alvar J. Leishmania/HIV co-infections: epidemiology in Europe. Ann Trop Med Parasitol. 2003;97 Suppl 1:3-15. http://dx.doi.org/10.1179/000349803225002499. PMid:14678629.

5. Gruev T. Contribution to the study of leishmaniasis (kala-azar) in Bulgaria. Medical records. 1949;8:845-55. Bulgarian.

6. Bratanov B. First contributions to autochthonous childhood visceral leishmaniasis in Bulgaria. Scientific Works - Internal and Pediatric Medicine. ISUL, 1952;113-58. Bulgarian.

7. Andreev I, Angelov A, Karapanchev B. Observation of cases of kala azar in childhood. Issues Ped Obst Gynec. 1958;2:38-46. Bulgarian.

8. Filipov G, Hristova T, Harizanov R, Mitkova N. On certain aspects of the epidemiology of visceral leishmaniasis. Disinfection Disinsection Deratization Bull. 2005;(1-4):24-8. Bulgarian.

9. Filipov G, Harizanov R, Jordanova D, Vuchev D, Kurdova R, Dimitrov H. Current state of visceral leishmaniasis in Bulgaria. Infectology. 2003;4:29-31. Bulgarian.

10. Filipov G, Harizanov R, Rusinova A, Rasheva G, Kaneva E, Chakarova B, et al. Visceral leishmaniasis in Bulgaria - past and present. Medicine and Pharmacy. 2004;III-IV:7-10. Bulgarian.

11. Kurdova R, Rainova I, Jordanova D, Harizanov R, Marinova I, Bikov I, et al. Situation of the local and imported parasitoses in Bulgaria during 2009. Information Journal of NCIPD. 2011;1:32. Bulgarian.

12. Popov G, Andreeva N, Georgiev A, Kuzmanova E. A case report of visceral leishmaniasis. Vutr Boles. 1991;30(2),121-5. Bulgarian. PMid:1654012.

13. Vutova K. Visceral leishmaniasis - clinical, laboratory features and treatment. Medical Review. 2007;3:26-31. Bulgarian.

14. Tsachev I, Papadajonakis M, Kontos V, Ivanov A, Chakarova B, Stojanchev K, et al. Seroepidemiology of Leishmania infantum exposure among healthy dogs in Bulgaria. Turk J Vet Anim Sci. 2007;31(1):73-4.

15. Tsachev I, Kyriasis ID, Boutsini S, Karagouni E, Dotsika E. First Report of Canine Visceral Leishmaniasis in Bulgaria. Turk J Vet Anim Sci. 2010;34(5):465-9.

16. Tsachev I. Exotic zoonoses among dogs in Bulgaria [dissertation]. Stara Zagora: Trakia University; 2009. Bulgarian.

17. Drenski P, Drenski K. Contribution to the study of genus Phebotomus (Dipt.) and the three-day fever in Bulgaria. Proceedings of the Bulgarian Entomological Society. 1928;4:31-56. Bulgarian.

18. Wagner R. Psychodidae. In: Soós A, Papp L, editors. Catalogue of palaearctic Diptera, Volume 2: Psychodidae - Chironomidae. Budapest: Académiai Kiadó. 1990;11-25.

19. Radev V, Sabev P, Kostova T, Katerinova I, Nedelchev N. Parasitic zoonoses associated with dogs and cats - conditions for the emergence and spread. Compendium of papers and posters - Anniversary Scientific Session. '110 years National Veterinary Diagnostic Research Institute'. 2011;147-51. Bulgarian.

20. Artemiev MM, Neronov VM. Distribution and ecology of sandflies of the Old World (genus Phlebotomus). Moscow: The USSR Committee for the UNESCO Programme on Man and the Biosphere (MAB). 1984; 208. Russian.

21. Ministry of Public Health. Instruction no $0-8 / 27.03 .1978$ on prophylactic, therapeutic and organizational measures for control of malaria and other tropical diseases. Sofia. 1978; 29 pp. Bulgarian.

22. Ministry of Health. Ordinance no 5/06.04.2006 on the diagnosis, prevention and control of local parasitic diseases. State Gazette 2006;40:83-90. Bulgarian.

23. Ministry of Health. Ordinance no 21/08.07.2011 on the order of registration, notification and reporting of infectious diseases. State Gazette 2011;52:29-61. Bulgarian.

24. Digital library of National Statistical Institute. Population of Bulgaria by years. [Accessed 30 Jul 2012]. Bulgarian. Available from: http://statlib.nsi.bg:8181/isisbgstat/SSP/isisframesbasic.html

25. Ranchov G. Biostatistics. Sofia: Eko Print. 2004; 182 Bulgarian.

26. Harizanov R. Visceral leishmaniasis. In: Kurdova R, editor. Parasitic zoonoses in humans. Sofia: National Centre of Infectious and Parasitic Diseases. 2008; 145-75. Bulgarian.

27. Bulgarian Ministry of Health. National Program for Prevention and Control of HIV/AIDS at the Ministry of Health; [Accessed 30 Jul 2012]. Bulgarian. Available from: http://www.aidsprogram. bg/static_info1.php?main=data

28. World Health Organization (WHO). Leishmaniasis. Burden of disease. [Accessed 30 Jul 2012]; Geneva: WHO. Available from: http://www.who.int/leishmaniasis/burden/en/

29. Alvar J, Aparicio P, Aseffa A, Den Boer M, Canavate C, Dedet $\mathrm{J}-\mathrm{P}$, et al. The relationship between leishmaniasis and AIDS: the second 10 years. Clin Microbiol Rev. 2008;21(2): 334-59. http://dx.doi.org/10.1128/CMR.00061-07. PMid:18400800. PMCid:PMC2292576.

30. World Health Organization Regional Office for Europe (WHO/ Europe). Centralized information system for infectious diseases (CISID). All infectious diseases (numbers of cases, incidence). Copenhagen: WHO. [Accessed 30 Jul 2012] Available from: http://data.euro.who.int/cisid

31. Alvar J, Vélez ID, Bern C, Herrero M, Desjeux P, Cano J, et al. Leishmaniasis Worldwide and Global Estimates of Its Incidence. 2012. PLoS One. 7(5):e35671. http://dx.doi. org/10.1371/journal.pone.0035671. PMid:22693548. PMCid:PMC3365071.

32. Dujardin JC, Campino L, Ca-avate C, Dedet JP, Gradoni L, Soteriadou K, et al. Spread of Vector-borne Diseases and Neglect of Leishmaniasis, Europe. Emerg Infect Dis. 2008;14(7):1013-18. http://dx.doi.org/10.3201/eid1407.071589. PMid:18598618. PMCid:PMC 2600355. 